\title{
Should Governments Use a Declining Discount Rate in Project Analysis?
}

\author{
Kenneth J. Arrow*, Maureen L. Cropper ${ }^{\dagger}$, Christian Gollier*, \\ Ben Groom ${ }^{\S}$, Geoffrey M. Heal ${ }^{\circledR}$, Richard G. Newell", \\ William D. Nordhaus ${ }^{\#}$, Robert S. Pindyck**, William A. Pizer ${ }^{\dagger \dagger}$, \\ Paul R. Portney \\ Martin L. Weitzman"III
}

\section{Introduction}

In project analysis, the rate at which future benefits and costs are discounted often determines whether a project passes the benefit-cost test. This is especially true of projects that have long time horizons, such as those aimed at reducing greenhouse gas (GHG) emissions. In the case of

*Stanford University; e-mail: arrow@stanford.edu.

†University of Maryland, College Park; e-mail: cropper@rff.org.

*Toulouse School of Economics; e-mail: christian.gollier@tse-fr.edu.

${ }^{\S}$ London School of Economics; e-mail: b.groom@lse.ac.uk.

`Columbia Business School; e-mail: gmh1@columbia.edu.

"Nicholas School of the Environment, Duke University; e-mail: richard.newell@duke.edu.

\#Cowles Foundation, Yale University; e-mail: william.nordhaus@yale.edu.

**Sloan School of Management, Massachusetts Institute of Technology; e-mail: rpindyck@mit.edu.

${ }^{\dagger}$ Sanford School of Public Policy, Duke University; e-mail: billy.pizer@duke.edu.

tuniversity of Arizona, Tucson; e-mail: pportney@email.arizona.edu.

${ }^{\$ S}$ University of Gothenburg; e-mail: thomas.sterner@economics.gu.se.

"I University of Sussex; e-mail: richard.tol@esri.ie.

"IIIHarvard University; e-mail: weitzman@fas.harvard.edu.

At a workshop held at Resources for the Future in September 2011, twelve of the authors were asked by the US Environmental Protection Agency (EPA) to provide advice on the principles to be used in discounting the benefits and costs of projects that affect future generations. Maureen L. Cropper chaired the workshop. Much of the discussion in this article is based on the authors' recommendations and advice presented at the workshop.

Review of Environmental Economics and Policy, volume 8, issue 2, Summer 2014, pp. 145-163 doi:10.1093/reep/reu008 
GHG emissions projects, the benefits of reduced GHG emissions last for centuries, but the mitigation costs are borne today and in the near future. This means that the ability of such projects to pass the benefit-cost test is especially sensitive to the rate at which future benefits are discounted.

In evaluating public projects, France and the United Kingdom use discount rate schedules in which the discount rate applied today to benefits and costs occurring in the future declines over time (HM Treasury 2003; Lebègue 2005). That is, the rate used today to discount benefits from year 200 to year 100 is lower than the rate used to discount benefits in year 100 to the present. In the United States, however, the Office of Management and Budget (OMB) recommends that project costs and benefits be discounted at a constant exponential rate (which, other things equal, assigns a lower weight to future benefits and costs than a declining rate), although a lower constant rate may be used for projects that affect future generations. ${ }^{1}$ These conflicting government approaches to discounting raise a familiar, but difficult, question: How should governments discount the costs and benefits of public projects, especially those that affect future generations?

This article seeks to answer this question, focusing in particular on the principles that should be used to determine the rates at which to discount the costs and benefits of regulatory programs. More specifically, we examine whether these principles suggest that project evaluation should use a declining discount rate (DDR) schedule (i.e., the approach followed in the United Kingdom and France) or a constant exponential rate (i.e., the current approach in the United States).

The basic argument for a DDR is simple: if shocks to the consumption discount rate (i.e., the rate at which society would trade consumption in year $t$ for consumption in the present) are uncertain but positively correlated, then the efficient result is a declining schedule of discount rates (Gollier 2012). Over the last decade, two branches of the literature have emerged concerning DDRs.

The first branch extends the Ramsey formula for discounting benefits and costs to allow for uncertainty in the rate of consumption growth. The theory of benefit-cost analysis dictates that the benefits and costs of a project that are certain should be converted to consumption units and discounted to the present using the consumption discount rate (e.g., Dasgupta, Marglin, and Sen 1972). ${ }^{2}$ This approach leads to the Ramsey discounting formula, in which the discount rate applied to net benefits at time $t$ equals the sum of the utility rate of discount (i.e., the rate that the utility of future generations is discounted) and the rate of growth in consumption between $t$ and the present, ${ }^{3}$ weighted by (minus) the elasticity of the marginal utility of consumption. ${ }^{4}$ This branch of the literature extends the Ramsey formula in order to examine

\footnotetext{
${ }^{1}$ For intragenerational projects, the OMB (2003) recommends that benefit-cost analyses be performed using a discount rate of 7 percent, representing the pretax real return on private investments, and also a discount rate of 3 percent, representing the "social rate of time preference."

${ }^{2}$ For simplicity, throughout the article we ignore uncertainty in the stream of benefits and costs associated with a project, effectively assuming that these have been converted to certainty-equivalents. This allows us to focus on the time pattern of risk-free discount rates.

${ }^{3}$ Here, and through the beginning of the next section, we focus on annualized versus annual or instantaneous rates. This allows for easier comparison with constant discounting.

${ }^{4}$ Formally, this is: $\rho_{t}=\delta+\eta \cdot g_{t}$, where $\rho_{t}$ is the discount rate, $\delta$ is the utility rate of discount, $\eta$ is the elasticity of the marginal utility of consumption, and $g_{t}$ is the rate of growth in consumption between $t$ and the present.
} 
conditions under which uncertainty in the rate of consumption growth can lead to a DDR (see Gollier 2012 for an extended survey).

The second branch of the DDR literature is based on the expected net present value (ENPV) approach. This approach was initially developed by Weitzman $(1998,2001,2007)$, who argued that the uncertainty about future discount rates justifies using a decreasing term structure (i.e., time pattern) of discount rates today. Computing ENPVs with an uncertain but constant discount rate is equivalent to computing net present values with a certain but decreasing discount rate, termed a certainty-equivalent discount rate. This means that if there is a probability distribution over the future discount rate under constant exponential discounting, we should use a declining term structure of discount rates today. Other researchers have estimated certainty-equivalent discount rates based on historical time series of interest rates (e.g., Groom et al. 2007; Hepburn et al. 2009; Newell and Pizer 2003).

The remainder of the article examines these two approaches to discounting in more detail and discusses how they might be implemented empirically. The next section discusses the use of the Ramsey formula as a basis for discounting and identifies the conditions under which uncertainty in the rate of growth in per capita consumption will lead to a DD. This is followed by a discussion of the ENPV approach. For each approach, we discuss the difficulties of using it to generate an empirical schedule of discount rates for regulatory impact analysis. We also compare the use of a DDR schedule with the current practice in the United States, which is dictated by OMB guidelines (OMB 2003). Finally, we examine the issue of whether the use of a DDR schedule will lead to time-inconsistent decisions. ${ }^{5}$ We conclude that the arguments in favor of a DDR are compelling and thus merit serious consideration by regulatory agencies in the United States.

\section{The Ramsey Formula as a Basis for Discounting}

In benefit-cost analysis, the consumption rate of discount is usually approached from the perspective of a social planner who wishes to maximize the social welfare of society (Dasgupta 2008; Goulder and Williams 2012). That is, the utility of persons alive at time $t$ is characterized by an increasing, strictly concave function of consumption (i.e., the marginal utility of consumption declines as consumption increases), ${ }^{6}$ and it is assumed that the planner maximizes the discounted sum of the utilities of current and future generations. ${ }^{7}$ This means that in evaluating investment projects, a social planner would be indifferent between $\$ 1$ received at time $t$ and a smaller amount received today if the marginal utility of the two amounts were equal. $^{8}$

\footnotetext{
${ }^{5} \mathrm{~A}$ decision is time inconsistent if the decision maker would want to reverse the decision in the future without receiving new information (i.e., based solely on the passage of time). It is well known that individuals who discount future utility using a DDR may make time-inconsistent decisions (Strotz 1955).

${ }^{6}$ Consumption can be broadly defined to include both market and non-market goods and services.

${ }^{7}$ In this article, $c_{t}$ represents the average consumption of people alive at time $t$. In an intergenerational context, $t$ is often interpreted as indexing different generations; however, this need not be the case. It can simply represent average consumption in different time periods, with there being some overlap of individuals across time periods. A discussion of models that distinguish between individuals within and across generations is beyond the scope of this article.

${ }^{8}$ Formally, $u^{\prime}\left(c_{0}\right) \varepsilon=e^{-\delta t} u^{\prime}\left(c_{t}\right)$, where $\varepsilon$ is the amount received today, $u$ is utility, and $c_{t}$ is consumption. $\delta$ is the utility rate of discount.
} 
This approach assumes that the planner's utility function is additively separable, the utility received from a given level consumption is constant over time, and future utility is discounted at the rate $\delta .{ }^{9}$ If we assume that the utility of consumption- $u(c)$-is isoelastic; that is, that the elasticity of marginal utility with respect to consumption is constant, ${ }^{10}$ then $\rho_{t}$, the annual consumption rate of discount between time 0 and time $t$, can be written using the familiar Ramsey formula

$$
\rho_{t}=\delta+\eta \cdot g_{t}
$$

where $\eta$ is (minus) the elasticity of marginal utility with respect to consumption, and $g_{t}$ is the annualized growth rate of consumption between time 0 and time $t^{11}$

In the Ramsey formula, $\delta$ is the rate at which society (i.e., the social planner) discounts the utility of future generations. A value of $\delta=0$ says that we judge the utility of future generations to contribute as much to social welfare as the utility of the current generation. For any generation, $\eta$ describes how fast the marginal utility of consumption declines as consumption increases. Higher values of $\eta$ imply that the marginal utility of consumption declines more rapidly as consumption increases. The standard interpretation of the Ramsey formula, shown in equation (1), is that, when $g_{t}$ is positive, the social planner will discount the utility of consumption of future generations because future generations are wealthier. To illustrate, if $g_{t}=1.3$ percent annually, per capita consumption in two hundred years will be more than thirteen times higher than today. So it makes sense to discount the utility of an extra dollar of consumption received two hundred years from now. Moreover, the planner will discount that utility at a higher rate the faster the marginal utility of consumption decreases as consumption rises.

\section{The Ramsey Formula When the Growth Rate of Consumption Is Uncertain}

The rate of growth in per capita consumption is likely to be uncertain, especially over long time horizons, and allowing for this uncertainty alters the Ramsey formula. To illustrate, we begin with the case in which shocks to consumption are independently and identically distributed (i.e., uncorrelated over time), which yields what is known as the extended Ramsey formula. If the growth rate of consumption is a sequence of random variables that are independently and identically normally distributed with mean $\mu_{g}$ and variance $\sigma_{g}{ }^{2}$, a third term is added to the Ramsey formula as a result of this uncertainty (Gollier 2002; Mankiw 1981), and

${ }^{9}$ Solving the equation in footnote 8 for $\varepsilon$, the present value of $\$ 1$ in year $t$,

$$
\varepsilon=\frac{e^{-\delta t} u^{\prime}\left(c_{t}\right)}{u^{\prime}\left(c_{0}\right)}=e^{-\rho_{t} t}
$$

where $\rho_{t}$ denotes the annual consumption rate of discount between periods 0 and $t$.

${ }^{10}$ Formally, $u(c)=c^{(1-\eta)} /(1-\eta)$.

${ }^{11}$ In the Ramsey formula, $\eta$ captures the intertemporal elasticity of substitution between consumption today and consumption in the future, the coefficient of relative risk aversion, and inequality aversion. As discussed more fully later, more sophisticated treatments (Epstein and Zin 1991; Gollier 2002; Weil 1990) separate attitudes toward time and risk. 
equation (1) becomes: ${ }^{12}$

$$
\rho_{\mathrm{t}}=\delta+\eta \mu_{g}-0.5 \eta^{2} \sigma_{g}^{2}
$$

The last term in equation (2) indicates a precautionary effect: that is, that uncertainty about the rate of growth in consumption reduces the discount rate, which causes the social planner to put more weight on the future. ${ }^{13}$ The magnitude of the precautionary effect is likely to be small, however, at least for the United States. As suggested by Gollier (2008) and Dasgupta (2008), suppose that $\delta=0$, and $\eta=2$. Using annual data from 1889 to 1978 for the United States, Kocherlakota (1996) estimated $\mu_{\mathrm{g}}$ to be 1.8 percent and $\sigma_{\mathrm{g}}$ to equal 3.6 percent. This implies that the precautionary effect is 0.26 percent and that $\rho=3.34$ percent (rather than 3.6 percent, as implied by the standard Ramsey formula. ${ }^{14}$ Thus uncertainty in consumption per se need not cause the discount rate to decline (nor substantially reduce it).

\section{Impact of catastrophic risks}

Shocks to consumption may have a larger impact on the discount rate if such shocks represent catastrophic risks. Pindyck and Wang (2013) examine how the risk of global events that would cause a substantial decline in either the capital stock or its productivity would affect discounting. Examples of such catastrophes include an economic collapse on the order of the Great Depression, nuclear or bioterrorism, a highly contagious "mega-virus" that kills large numbers of people, or an environmental catastrophe, such as the West Antarctic Ice Sheet sliding into the sea. Pindyck and Wang (2013) find that if $\eta=2$, such catastrophes could reduce the discount rate by -1.2 percent to -1.6 percent. $^{15}$

\section{Uncertain consumption and the declining discount rate}

Equation (2) illustrates that independently and identically normally distributed shocks to consumption growth with known mean and variance result in a constant consumption rate of discount. However, the consumption rate of discount may decline over time if shocks to consumption growth are positively correlated over time, or if the rate of change in consumption is independently and identically distributed with unknown mean or variance. Gollier (2012, Chapter 8) shows that if shocks to consumption growth are positively correlated and the utility of consumption $(u(c))$ is isoelastic, the annual consumption rate of discount $\left(\rho_{t}\right)$ will decline. ${ }^{16}$ The intuition behind this is that positive shocks to consumption make future consumption

\footnotetext{
${ }^{12}$ More precisely, we assume that $\ln \left(c_{i} / c_{i-1}\right)$ is independently and identically normally distributed with mean $\mu_{g}$ and variance $\sigma_{g}^{2}$.

${ }^{13} \mathrm{~A}$ necessary condition for this to hold is that the planner be prudent (i.e., that the third derivative of $u(c)$ be positive), which is satisfied by the isoelastic utility function.

${ }^{14}$ Gollier (2011) finds that the size of the precautionary effect is much larger for other countries, especially developing countries.

${ }^{15}$ Formally, they suppose that catastrophic risk is modeled as a Poisson process with mean arrival rate $\lambda$, and that if a catastrophe occurs, consumption falls by a random percentage $\xi$. This subtracts $\eta \lambda E(\xi)$ from the right-hand side of (2), thus reducing the discount rate. How important is this last term? Recent estimates of $\lambda$ and $E(\xi)$ based on panel data by Barro $(2006,2009)$ and others put $\lambda \approx .02$ and $E(\xi) \approx 0.3$ to 0.4 .

${ }^{16}$ Formally, Gollier shows that if $\ln \left(c_{i} / c_{i-1}\right)$ exhibits "positive quadrant dependence" and $\mathrm{u}^{\prime \prime \prime}(\mathrm{c})>0, \rho_{t}$ will decline as $t$ increases.
} 
riskier, thus increasing the strength of the precautionary effect in equation (2) for distant time horizons. $^{17}$

Various models of per capita consumption growth have been estimated for the United States (e.g., Cecchetti, Lam, and Mark 2000; Cochrane 1988) that could be used empirically to estimate a DDR using the extended Ramsey formula. The positive correlation in the rate of change in per capita consumption in the United States (based on historical data) is likely to result in a discount rate that declines slowly over time. Based on estimates in the literature for the United States, Gollier (2008) reports an estimated precautionary effect of 0.3 , which implies a very gradual decline in the discount rate. The discount rate is also estimated to decline very gradually based on the regime-switching model of Cecchetti et al., who find that the efficient discount rate in the positive growth regime declines from 4.3 percent today to 3.4 percent after a hundred years.

\section{Subjective uncertainty}

The approach we have presented for parameterizing the extended Ramsey formula is based on the assumption that the nature of the stochastic consumption-growth process can be adequately characterized by econometric models that are estimated using historical data. However, the consumption-based asset pricing literature suggests that this may not be the case. ${ }^{18}$ To quote Weitzman (2007), "People are acting in the aggregate like there is much more... subjective variability about future growth rates than past observations seem to support." This argues for treating the mean $\left(\mu_{g}\right)$ and variance $\left(\sigma_{g}\right)$ of consumption growth as uncertain, and, as shown in Weitzman $(2004,2007)$ and Gollier (2008), this subjective uncertainty about the trend and volatility in consumption growth will lead to a DDR.

The form of the planner's subjective uncertainty about the mean rate of growth in consumption will clearly influence the path of the efficient discount rate. For example, the assumptions made in Weitzman (2004) cause the efficient discount rate to decline linearly, eventually becoming negative. However, Gollier (2008) presents examples that yield nonnegative paths for the efficient discount rate.

Gollier (2008) proves that when the rate of growth in consumption is a sequence of random variables as before, but the mean rate of growth depends on an uncertain parameter, ${ }^{19}$ the discount rate will decline over time. Figure 1 demonstrates the path of the discount rate $\left(R_{t}\right)$ for the case of $\delta=0, \eta=2$, and $\sigma_{g}=3.6$ percent. The mean rate of growth in consumption is assumed to equal 1 percent and 3 percent with equal probability, which yields a discount rate that declines from 3.8 percent today to 2 percent after three hundred years-a path that closely resembles France's discounting schedule (see Figure 2). ${ }^{20}$ Other distributions for the uncertain

\footnotetext{
${ }^{17}$ To illustrate, shocks to consumption could take a form where $\ln \left(c_{t} / c_{t-1}\right) \equiv x_{t}$ (the percentage growth in consumption at $t$ ) follows a first-order autoregressive moving average (i.e., $\mathrm{AR}(1))$ process: $x_{t}=\varphi x_{t-1}+(1-$ $\varphi) \mu+u_{t}$, with $u_{t}$ independently and identically normally distributed with constant variance. Mathematically, this equation will generate a declining discount rate on average, provided $0<\varphi<1$. To be precise, the precautionary effect is multiplied by the factor $(1-\varphi)^{-2}$ as $t$ goes to infinity (Gollier 2008).

${ }^{18}$ For example, the extended Ramsey formula does a poor job of explaining the equity premium puzzle: the large gap between the mean return on equities and risk-free assets (Weitzman 2007).

${ }^{19}$ The uncertain parameter is $\theta\left[\mu_{g}=\mu_{g}(\theta)\right]$. $\theta$ might, for example, be related to the rate of technical progress.

${ }^{20} R_{t}$ is the rate that would be used to discount benefits or costs at time $t$ back to time 0 . The $R_{t}$ path is labeled the "effective term structure" in Figure 2.
} 


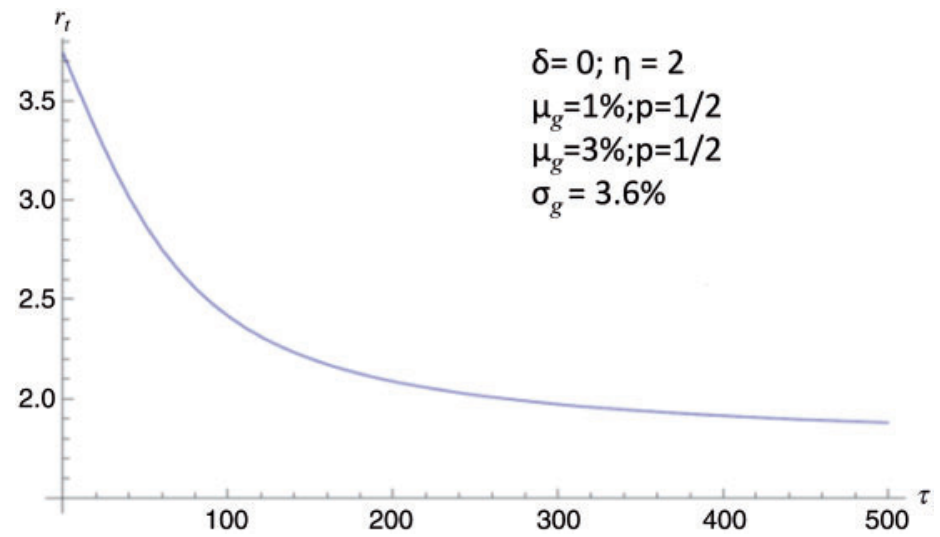

Figure I Certainty-equivalent discount rate assuming consumption growth is a sequence of independent random variables with uncertain mean $(\mu=\mu(\theta))$

Source: Gollier (2008).

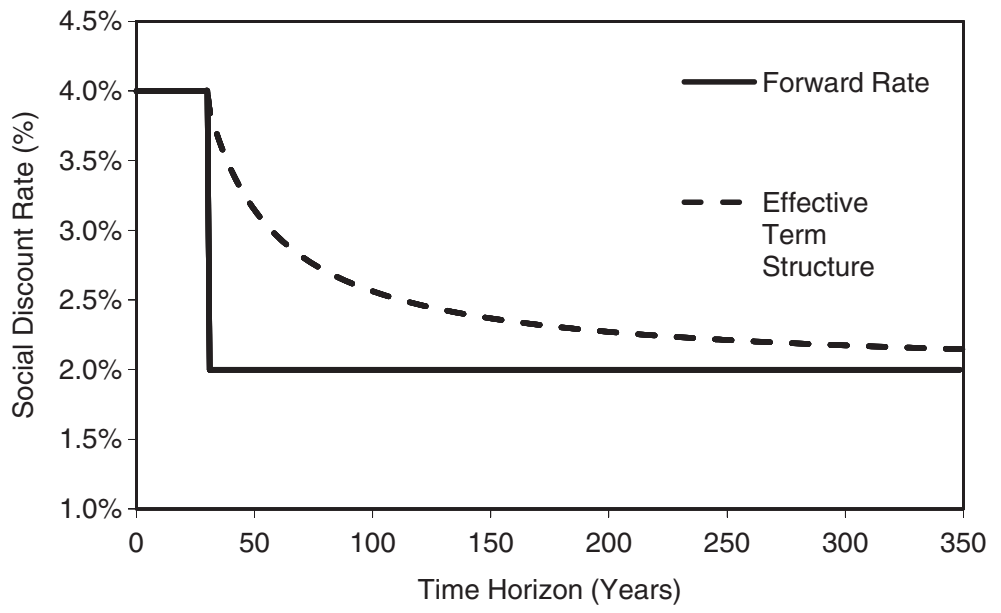

Figure 2 The French government social discount rate term structure

Notes: The forward rate is the rate used to discount benefits and costs from year $t+1$ back to year $t$. The effective term structure gives the rate used to discount benefits and costs from year $t$ back to year 0 . Source: Lebègue (2005).

parameter will, of course, lead to other DDR paths. The point is that uncertainty about the rate of consumption growth that is positively correlated over time will lead to a DDR.

\section{Options for Parameterizing the Ramsey Formula}

To empirically implement a DDR using the extended Ramsey formula requires estimates of $\delta$ and $\eta$ as well as information about the process governing the growth of per capita consumption. Here we discuss both prescriptive and descriptive options for quantifying $\delta$ and $\eta$.

\section{Estimating $\delta$ and $\eta$ as normative parameters}

Many economists view the Ramsey approach to discounting, which underlies the theory of benefit-cost analysis, as a normative approach (e.g., Arrow et al. 1996; Dasgupta 2008). This 
implies that the parameters $\delta$ and $\eta$ should reflect how society values consumption by individuals at different points in time; that is, that $\delta$ and $\eta$ should reflect social values. The question is how these values should be measured.

Many—but not all—of the authors of this article agree with Frank Ramsey (Ramsey 1928) that it is ethically indefensible to discount the utility of future generations, except possibly to account for the fact that these generations may not exist. This implies that $\delta=0$, or some number that reflects the probability that future generations will not be alive. Stern (2006), for example, assumes that the hazard rate of extinction of the human race is 0.1 percent per year. It is important to emphasize, however, that while setting $\delta=0$ may reflect the ethical beliefs of some people, it need not reflect the values of society at large. Furthermore, this value for $\delta$ is based not on economic principles but rather on personal beliefs.

The parameter $\eta$ plays three roles in the Ramsey formula: (a) it is inversely related to the intertemporal elasticity of substitution between consumption today and consumption in the future; (b) it represents the coefficient of relative risk aversion; and (c) it reflects intergenerational inequality aversion. This complicates the estimation of $\eta$ because researchers will obtain different values for $\eta$ depending on which role is emphasized (Atkinson et al. 2009; Groom and Maddison 2013). One could also argue (see Traeger 2009) that discounting should be based on a more complex characterization of preferences than simply those that underlie the Ramsey formula; for example, Epstein-Zin-Weil (EZW) recursive preferences (Epstein and Zin 1991; Weil 1990) separate risk aversion from the elasticity of intertemporal substitution of consumption. Although EZW preferences have been useful in explaining the behavior of financial markets, it is not clear to the authors of this article that they provide an appropriate foundation for social preferences.

Therefore we adhere to the Ramsey formula and argue that from a normative perspective, $\eta$ should be interpreted as reflecting the maximum sacrifice one generation should make to transfer income to another generation (Dasgupta 2008; Gollier, Koundouri, and Pantelidis 2008). ${ }^{21}$

\section{Estimating $\delta$ and $\boldsymbol{\eta}$ through observed behavior in public policy}

How should $\eta$ be determined empirically? One approach would be to examine the value of $\eta$ that is revealed by society's decisions to redistribute income, such as through progressive income taxes. For example, in the United Kingdom, such socially revealed inequality aversion (based on income tax schedules) has fluctuated considerably since World War II, with a mean of 1.6 (Groom and Maddison 2013). However, if we were to apply this value to climate policy we would be making the implicit assumption that (a) the UK government has made the "right" choice concerning income redistribution and (b) income redistribution within a country and period is the same as income redistribution between countries and over time. Tol (2010) estimates the consumption rate of international inequality aversion (revealed by decisions on the level and allocation of development aid) to be 0.7 . Thus the appropriate value of $\eta$ revealed by societal decisions remains uncertain.

\footnotetext{
${ }^{21}$ To further illustrate this concept, Appendix Table A1 indicates the maximum sacrifice that society believes a higher income group (A) should make to transfer $\$ 1$ to the poorer income group (B), as a function of $\eta$. When group A is twice as rich as group B and $\eta=1$, the maximum sacrifice is $\$ 2$; when $\eta=2$, the maximum sacrifice is $\$ 4$.
} 
Another option for eliciting values of $\eta$ and $\delta$ would be to use stated preference methods. The issue here is whose preferences should be examined and how. As Dasgupta (2008) has pointed out, it is important to examine the implications of the choice of $\eta$ and $\delta$ for the fraction of output that a social planner chooses to save. Ceteris paribus, a lower value of $\eta$ implies that society would choose to save a larger proportion of its output in order to increase the welfare of future generations. Thus the implications of the choice of $\delta$ and $\eta$ for societal savings rates would need to be made clear to those surveyed. ${ }^{22}$

However, some of the authors are skeptical of the validity of using stated preference methods, especially when applied to laypeople who may not appreciate theoretical constructs such as "pure time preference," "risk-free investment," and "benevolent social planner." We suggest comparing the values of $\rho_{t}$ with the return on risk-free investment as a way to verify that the results obtained from direct questioning methods are reasonable. While the return on risk-free investment may not represent the consumption rate of discount, it is currently viewed as a surrogate for the consumption rate of discount by the OMB (2003), and it is more readily observable than the consumption rate of discount.

\section{Estimating $\delta$ and $\eta$ through observed behavior in financial markets}

In the simple Ramsey formula, the parameter $\eta$ also represents the coefficient of relative risk aversion. $^{23}$ This suggests that $\eta$ could be estimated from observed behavior of macroeconomic aggregates and financial markets. ${ }^{24}$ Although some of the authors favor this approach, others object to the use of such estimates because they do not reflect intergenerational consumption tradeoffs, which makes them inappropriate as estimates of $\eta$ in a social welfare function.

The use of financial market data to estimate $\eta$ also raises the broader issue of whether the consumption rate of discount should reflect observed behavior and/or the opportunity cost of capital. The descriptive approach to social discounting (Arrow et al. 1996), clearly reflected in Nordhaus $(1994,2007)$, suggests that $\delta$ and $\eta$ should be chosen so that the consumption rate of discount $\left(\rho_{t}\right)$ approximates market interest rates. Baseline runs of the 2007 Dynamic Integrated Climate-Economy (DICE) model assume that $\delta=1.5$ and $\eta=2$ (Nordhaus 2007). ${ }^{25}$ In DICE 2007, $\rho_{t}$ ranges from 6.5 percent in 2015 to 4.5 percent in 2095 as consumption growth slows over time (Nordhaus 2007). These are clearly larger values for $\rho_{t}$ than described at the beginning of this section.

These results raise the question: Should we expect $\rho_{t}$-the consumption rate of discount in the Ramsey formula - to equal the rate of return to capital in financial markets, and, if not, what should we do about it? In an optimal growth model (e.g., the Ramsey model), the consumption rate of discount will equal the marginal product of capital along an optimal consumption path. If, for example, the social planner chooses the path of society's consumption in a one-sector

\footnotetext{
${ }^{22}$ There is also an issue of how to aggregate preferences. One approach to this problem is to characterize equilibrium discount rates in an economy in which agents differ in their rate of time preference (Gollier and Zeckhauser 2005) and possibly in their assumptions about future growth in consumption (Jouini, Marin, and Napp 2010).

${ }^{23}$ Relative risk aversion concerns the proportion of wealth that risk-averse investors are willing to put at risk as their wealth increases. People whose utility function exhibits constant relative risk aversion will keep the proportion of wealth invested in a risky asset constant as their wealth increases.

${ }^{24}$ The macroeconomic literature on the coefficient of relative risk aversion is summarized by Meyer and Meyer (2005). Groom and Maddison (2013) review the literature on the elasticity of intertemporal substitution.

${ }^{25}$ DICE is an optimal growth model in which $g_{t}$ and $\rho_{t}$ are determined endogenously.
} 
growth model, the consumption rate of discount $-\rho_{t}$-will equal the marginal product of capital along an optimal path. But what if society is not on an optimal consumption path? In this case, theory tells us that we need to calculate the social opportunity cost of capital - that is, we need to evaluate the present discounted value of consumption that a unit of investment displaces, and then use it to value the capital used in a project when we conduct a benefit-cost analysis (Dasgupta et al. 1972). However, once this is done (i.e., once all quantities have been converted to consumption equivalents), the appropriate discount rate for judging whether a project increases social welfare is indeed the consumption rate of discount $\left(\rho_{t}\right)$ (Dasgupta et al. 1972). Thus, in theory, differences between the rate of return to capital and the consumption discount rate can be resolved.

One potential problem with this approach is that converting all costs and benefits to consumption units can be difficult in practice. This suggests using the rate of return to capital as the discount rate when a project displaces private investment. In fact, this is what the OMB recommends when it suggests using a 7 percent real discount rate. A discount rate of 7 percent is "an estimate of the average pretax rate of return on private capital in the U.S. economy" (OMB 2003) and is meant to capture the opportunity cost of capital when "the main effect of the regulation is to displace or alter the use of capital in the private sector."

\section{The Expected Net Present Value Approach}

We have argued in the previous section that the Ramsey formula provides a theoretical basis for intergenerational discounting and that it also suggests the discount rate schedule is likely to decline over time due to uncertainty about the rate of growth in per capita consumption.

An alternative approach to modeling discount rate uncertainty is the ENPV approach. Suppose that an analyst discounts net benefits at time $t(Z(t))$ to the present using a constant exponential rate $r$, so that the present value of net benefits at time $t$ equals $Z(t) \exp (-r t) .{ }^{26}$ If the discount rate $r$ is fixed over time but uncertain, then the expected value of net benefits is given by

$$
A(t) Z(t)=E(\exp (-r t)) Z(t)
$$

where the expectation is taken with respect to $r$, and $A(t)$ is the expected value of the discount factor. The certainty-equivalent discount rate $R_{t}$, which is used to discount net benefits at time $t$ to the present, is defined by

$$
\exp \left(-R_{t} t\right)=E(\exp (-r t))^{27}
$$

The instantaneous certainty-equivalent discount rate, or forward rate, is given by the rate of change in the expected discount factor $\left(F_{t}\right) .{ }^{28}$ This is the rate at which benefits in period $t$ would be discounted back to period $t-1$. Because the discount factor is a convex function of $r$, the

\footnotetext{
${ }^{26} \mathrm{We}$ assume that $Z(t)$ represents certain benefits. If benefits are uncertain we assume that they are uncorrelated with $r$ and that $Z(t)$ represents certainty-equivalent benefits. A referee noted that this approach is at odds with the approach in corporate finance, in which discount rates are adjusted to reflect the riskiness of a project.

${ }^{27}$ This implies that $R_{t}=-1 / t \ln \left[A_{t}\right]$.

${ }^{28}$ Formally, the instantaneous certainty equivalent rate (forward rate) is $-\left(d A_{t} / d t\right) / A_{t} \equiv F_{t}$
} 


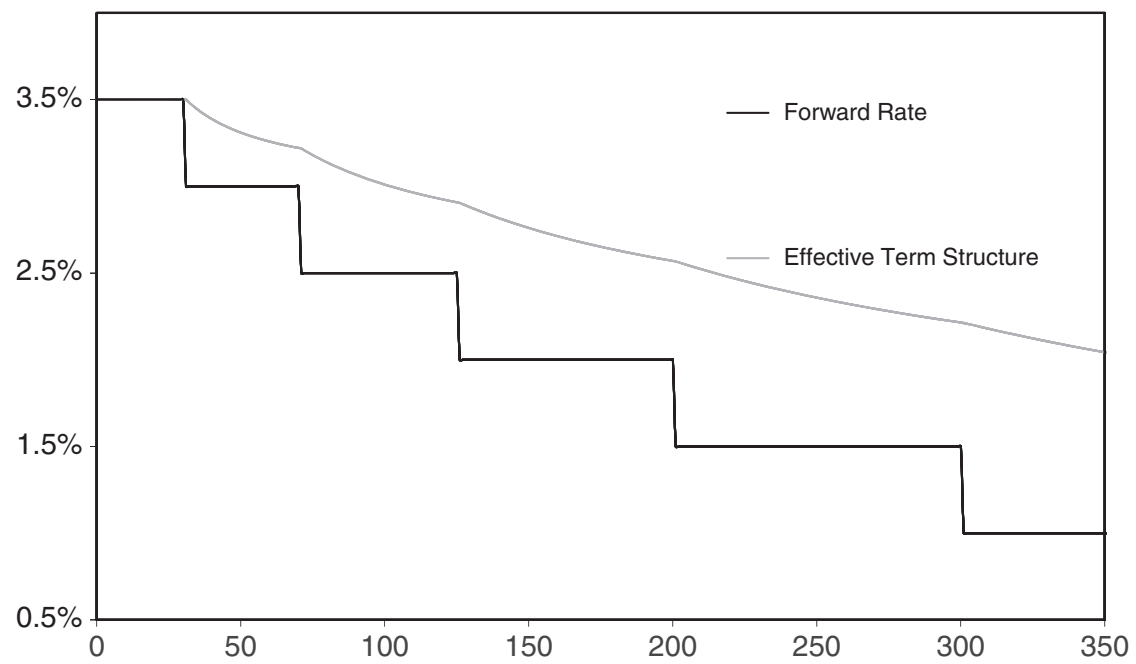

Figure 3 The UK government social discount rate term structure

Notes: The forward rate is the rate used to discount benefits and costs from year $t+1$ back to year $t$. The effective term structure gives the rate used to discount benefits and costs from year $t$ back to year 0 . Source: HM Treasury (2003).

certainty-equivalent discount rate and the forward rate will both decline over time (Weitzman 1998, 2001). ${ }^{29}$

Figures 2 and 3 show the forward rates and the corresponding certainty-equivalent rates (labeled "Effective Term Structure") used by France and the United Kingdom, respectively. The forward rate in France is 4 percent each year between the present and thirty years in the future, falling to 2 percent per year thereafter. This implies that for benefits and costs occurring thirty years (or fewer) in the future, the certainty-equivalent discount rate is 4 percent, and falls thereafter. ${ }^{30}$ More specifically, the certainty-equivalent rate falls to 2 percent for benefits and costs occurring three hundred years in the future. The forward rate in the United Kingdom is given by a step function (see Figure 3), which implies a certainty-equivalent rate of 3.5 percent for benefits and costs occurring thirty or fewer years in the future. This rate declines to 2 percent for benefits and costs occurring 350 years in the future.

The fact that forward-and hence certainty-equivalent-discount rates decline was first raised by Weitzman $(1998,2001)$ in the context of intergenerational discounting. ${ }^{31}$ In his article "Gamma Discounting," Weitzman (2001) characterized uncertainty about the discount rate $(r)$ using a gamma distribution, ${ }^{32}$ which provided a good fit to the responses Weitzman obtained when he asked more than two thousand $\mathrm{PhD}$ economists what rate should be used to discount the costs and benefits associated with programs to mitigate climate change. The associated

\footnotetext{
${ }^{29}$ This result follows mathematically from Jensen's inequality, which states that the expected value of a convex function of a random variable is greater than the function of the mean of the random variable, that is, $E(\exp (-r t))>\exp (-E(r) t))$. Together with equation (4), this implies that $R_{t}$ must be less than the mean of $r$. This effect is magnified as $t$ increases.

${ }^{30}$ The discount factor used to discount benefits in year $t>30$ to the present is given by $\exp \left(-\left(0.04^{\star} 30+0.02^{\star}\right.\right.$ $(t-30)))$.

${ }^{31}$ Gollier and Weitzman (2010) discuss the theoretical underpinnings for the ENPV approach, which is consistent with utility maximization in the case of a logarithmic utility function.

${ }^{32}$ See http://en.wikipedia.org/wiki/Gamma_distribution.
} 
Table I. Forward discount rate schedule

\begin{tabular}{llc}
\hline Time period & Name & Marginal Discount Rate (Percent) \\
\hline Within years I to 5 hence & Immediate Future & 4 \\
Within years 6 to 25 hence & Near Future & 3 \\
Within years 26 to 75 hence & Medium Future & 2 \\
Within years 76 to 300 hence & Distant Future & I \\
Within years more than 300 hence & Far-Distant Future & 0 \\
\hline
\end{tabular}

Source: Weitzman (200I).

mean ( 4 percent) and standard deviation ( 3 percent) of responses are the basis for the schedule of forward rates presented in Table 1.

\section{Underlying Source of Uncertainty}

It is important, however, to consider the underlying source of uncertainty that generates a DDR schedule. There are differences in opinion concerning how the future will unfold with regard to returns to investment, growth, and hence the discount rate. Clearly, there is genuine uncertainty about these quantities over long time horizons. However, Weitzman (2001) argued that this disagreement among experts represents only the "tip of the iceberg" compared to the differences in normative opinions on the issue of intergenerational justice. Rather than reflecting uncertainty about the future interest rate, which falls naturally into the positive (i.e., descriptive) realm, variation in normative opinions reflects irreducible differences on matters of ethics. In this case, variation reflects heterogeneity, not uncertainty. We believe that disagreement among experts that reflects differing opinions or preferences is in a different category than underlying uncertainty about the economy, and thus they require different approaches. Gollier and Zeckhauser (2005) and Heal and Millner (2013) show that efficient allocation in the face of heterogeneous time preferences can cause a declining utility discount rate, which can drive a declining consumption discount rate. However, combining heterogeneous time preferences is a fundamentally different approach to generating a DDR.

In contrast, if the opinions of experts represent forecasts, Freeman and Groom (forthcoming) argue that these forecasts should be combined in order to reduce forecasting error, as is typical in the literature (e.g., Bates and Granger 1969). In situations where there are differences in opinions but the experts are unbiased and form their forecasts independently, the appropriate measure of variation is the standard error. Freeman and Groom (forthcoming) show that in this case, the most appropriate methods of combining forecasts lead to a much slower decline in the discount rate than the original Weitzman (2001) approach. ${ }^{33}$

In "Gamma Discounting" (Weitzman 2001), the declining forward rate follows directly from Jensen's inequality (see footnote 29) and a constant but uncertain exponential discount rate. The more general case in which the discount rate varies over time gives us

$$
A(t)=E\left[\exp \left(-\sum_{\tau=1 \ldots t} r_{\tau}\right)\right]
$$

${ }^{33}$ Generally, Freeman and Groom (forthcoming) suggest that the decline in the discount rate will be more rapid the greater the dependence between expert forecasts. 
In this case, the shape of the path of forward rates $\left(F_{t}\right)$ depends on the distribution of the per period discount rate $\left\{r_{\tau}\right\}$. If $\left\{r_{\tau}\right\}$ are independently and identically distributed, the forward rate is constant. In equation (5), in order for the forward rate to decline, there must be positive correlation in uncertainty about the discount rate. If shocks to the discount rate are correlated over time, as in equation (6),

$$
r_{t}=\pi+e_{t} \text { and } e_{t}=a e_{t-1}+u_{t}, \quad|a| \leq 1
$$

the forward rate will decline over time (Newell and Pizer 2003). ${ }^{34}$

\section{Empirical Estimates of the DDR Schedule for the United States}

The empirical DDR literature generally assumes that the future stochastic behavior of the discount rate $\left(r_{t}\right)$ can be modeled using historical market returns on the least risky investments available over time-typically government Treasury bonds. ${ }^{35}$ This literature includes models of interest rate determination for the United States (Groom et al. 2007; Newell and Pizer 2003); Australia, Canada, Germany, and the United Kingdom (Gollier et al. 2008; Hepburn et al. 2009); and France, India, Japan, and South Africa (Gollier et al. 2008). However, we focus here on the empirical DDR literature that concerns the United States.

\section{Reduced Form Models}

Using two centuries of data on long-term, high-quality government bonds (primarily US Treasury bonds), Newell and Pizer (2003) estimate reduced-form models of US bond yields, which they then use to estimate forward rates over the next four hundred years. They assume that interest rates follow an autoregressive process, ${ }^{36}$ which means that the mean interest rate is uncertain and deviations from the mean interest rate will be more persistent the higher is the correlation between shocks to the interest rate; that is, the higher is $a$ in equation (6). ${ }^{37}$ When $a=1$, interest rates follow a random walk (i.e., the sum of a sequence of independently and identically distributed normal random variables) and the forward rate will decline more rapidly than when $a<1$ (i.e., interest rates follow a mean-reverting model). In the random walk model, Newell and Pizer (2003) find that the forward rate falls from 4 percent today to 2 percent in a hundred years. However, in the mean-reverting model, a forward rate of 2 percent is not reached for three hundred years. ${ }^{38}$

\footnotetext{
${ }^{34}$ In equation (6), the interest rate follows an $\operatorname{AR}(1)$ process (see footnote 17). In estimating (6) it is typically assumed that $\pi \sim \mathrm{N}\left(\mu_{\pi}, \sigma_{\pi}^{2}\right)$, and $\left\{u_{t}\right\} \sim$ i.i.d. $\mathrm{N}\left(0, \sigma_{\mathrm{u}}^{2}\right)$.

${ }^{35}$ The stochastic models estimated from historical behavior can be applied to different starting values. This separates the assumption of the right "rate" from how that rate varies over time.

${ }^{36}$ This is given by $r_{t}=\pi+e_{t}$ and $e_{t}=a e_{t-1}+u_{t},|a| \leq 1$ in the case of $\operatorname{AR}(1)$; see equation (6). The authors estimate autoregressive models in the logarithms of the variables $\left(\ln r_{t}=\ln \pi+e_{t}\right)$ to avoid negative interest rates. Their preferred models are $\operatorname{AR}(3)$ models in which $e_{t}=a_{1} e_{t-1}+a_{2} e_{t-2}+a_{3} e_{t-3}+u_{t}$.

${ }^{37}$ The authors demonstrate that the instantaneous certainty-equivalent (forward) interest rate corresponding to (6) is given by $F_{t}=\mu_{\pi}-t \sigma_{\pi}{ }^{2}-\sigma_{u}{ }^{2} f(a, t)$, where $f(a, t)$ is increasing in $a$ and $t$. How fast the forward rate declines depends on the variance in the mean interest rate as well as on the persistence of shocks to the mean interest rate (i.e., on $a$ ).

${ }^{38}$ The point estimate of $a_{1}+a_{2}+a_{3}=0.976$ with a standard error of 0.11 , implying that Newell and Pizer (2003) can reject the mean-reverting model. The authors also note that when the mean-reverting model is estimated using data from 1798 through 1899, it overpredicts interest rates in the first half of the twentieth century.
} 


\section{More Flexible Reduced Form Models}

The subsequent DDR literature for the United States, which is modeled after the finance literature, has estimated more flexible reduced-form models of interest rate determination. For example, Groom et al. (2007) use the same data as Newell and Pizer (2003) to estimate five models for the United States. The first two models are random walk and mean-reverting models that are identical to those in Newell and Pizer (2003). The third model is an autoregressive integrated generalized autoregressive conditional heteroscedasticity (AR-IGARCH) model that allows the conditional variance of the interest rate to vary over time. The fourth model is a regime-switching model that allows the interest rate to shift randomly between two states that differ in their mean and variance. The fifth model, which outperforms the others in within- and out-of-sample predictions, is a state-space model-an autoregressive model that allows both the degree of mean reversion and the variance of the process to change over time. ${ }^{39}$ The state-space model of Groom et al. (2007) suggests that the forward rate initially declines more rapidly than in the Newell and Pizer (2003) random walk model but approaches a higher discount rate in the long run. Freeman et al. (2013) further extend the DDR literature by adjusting the data series used by Newell and Pizer (2003) and Groom et al. (2007) for inflation. ${ }^{40}$ They find that a declining DDR is robust to a more rigorous treatment of inflation.

\section{Forward Rates and the Social Cost of Carbon}

Figure 4 presents estimates of the forward rates for the United States from the random walk model of Newell and Pizer (2003), the state-space model of Groom et al. (2007), and the preferred model of Freeman et al. (2013). ${ }^{41}$ For the first one hundred years, the forward rates from the state-space model decline more rapidly than those produced by the random walk model, leveling off at about 2 percent. The random walk model yields a forward discount rate of 2 percent at year 100 and 1 percent in year 200, declining to about 0.5 percent when $t=400$. The DDR path corresponding to Freeman et al. (2013) is initially higher than Groom et al. (2007), but declines more rapidly than Newell and Pizer (2003) for longer time horizons. Clearly, the precise form of the path of forward rates is sensitive to the specific model estimated.

The DDR schedules presented in Figure 4 have a significant impact on estimates of the social cost of carbon, relative to estimates that are based on a constant exponential discount rate of 4 percent. All three sets of authors use damage estimates from Nordhaus (1994) to calculate the marginal social cost of carbon as the present discounted value of global damages from emitting a ton of carbon in 2000, discounted at a constant exponential rate of 4 percent and using forward rates from their models. Using a constant exponential rate of 4 percent, the social cost of carbon is $\$ 10.70$ (2013 US\$). However, the social cost of carbon is $\$ 19.50$ per ton of carbon using the random walk model in Newell and Pizer (2003), \$27.00 per ton using the state-space

\footnotetext{
${ }^{39}$ In the state-space model $r_{t}=\pi+a_{t} r_{t-1}+e_{t}$, where $a_{t}=\sum \lambda_{i} a_{t-1}+u_{t} \cdot e_{t}$ and $u_{t}$ are serially independent, zero-mean, normally distributed random variables, whose distributions are uncorrelated. The authors compare the models using the root mean squared error of within- and out-of-sample predictions.

${ }^{40}$ Newell and Pizer (2003) and Groom et al. (2007) use annual market yields on long-term government bonds for the period 1798-1999. Starting in 1950, nominal interest rates are converted to real ones using the expected rate of inflation forecast by the Livingston Survey of professional economists (Thomas 1999).

${ }^{41}$ The preferred model in Freeman et al. (2013) is an augmented autoregressive distributed lag model. Simulations have been run for all three models assuming a mean interest rate of 4 percent per annum.
} 


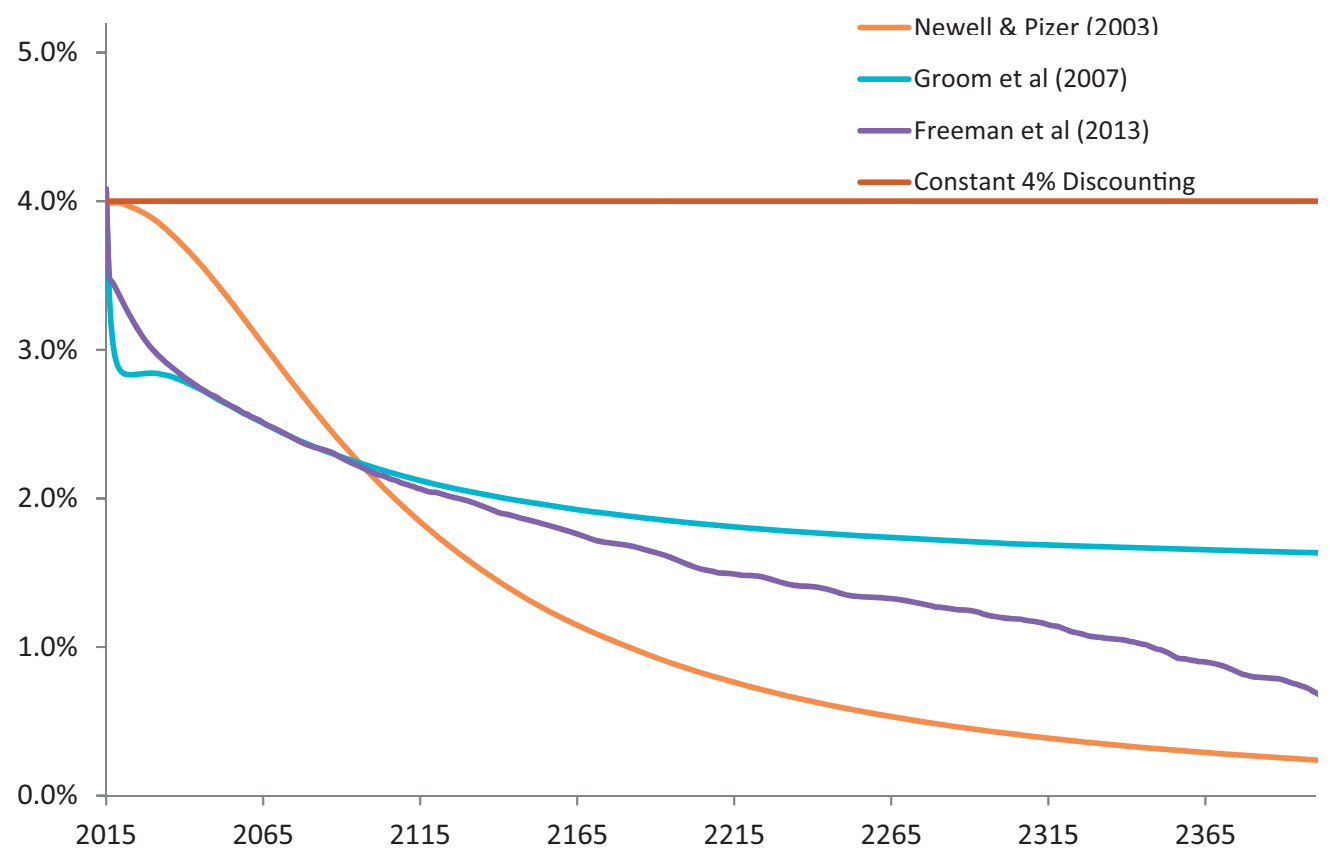

Figure 4 Estimates of forward rates for the United States

Source: Newell and Pizer (2003), random walk model; Groom et al. (2007), state-space model; Freeman et al. (20I3), augmented autoregressive distributed lag model.

model in Groom et al. (2007), and \$26.10 per ton using the preferred model in Freeman et al. (2013) (2013 US\$). This suggests that the use of a DDR could possibly increase estimates of the social cost of carbon.

\section{The DDR and Time Consistency}

One issue that frequently arises in the context of the DDR is whether the use of a DDR will lead to time-inconsistent decisions. It is well known that an individual who discounts the future hyperbolically (i.e., assigns higher discount rates to utility in the near term than in the distant term), will not - at time $t$-wish to follow a consumption-savings plan that was made at time 0 (Strotz 1955). The problem is this: at time 0 the discount rate between period $t$ and $t+1$ is a long-term (low) discount rate. But, when period $t$ actually arrives, the individual will apply a short-term (high) discount rate to period $t+1$. Therefore, the individual will want to consume more in period $t$ than he had planned to consume when he formulated his plans at time 0 . The fact that the individual wishes to change his decision due simply to the passage of time means that his decision is time inconsistent.

However, it is also well known (Gollier et al. 2008) that a policy chosen by a decision maker who maximizes a time-separable expected utility function will be time consistent if expected utility is discounted at a constant exponential rate. ${ }^{42}$ In the Ramsey framework,

${ }^{42}$ Constant exponential discounting is a sufficient but not necessary condition for time consistency. See Heal (2005) for other conditions that will yield time-consistent decisions. However, it is necessary for an optimal policy to be both time consistent and stationary. 
this means that if a social planner discounts the utility of future generations at a constant exponential rate, the DDR that results from utility maximization will not lead to time-inconsistent decisions.

However, the problem of time consistency can arise in an ENPV framework if the DDR schedule does not change over time. For example, if, in 2012, an analyst were to evaluate future net benefits using the discounting schedule in "Gamma Discounting" (Weitzman 2001), but the schedule did not change over time, then, depending on the time pattern of net benefits, a program that passed the benefit cost test in 2012 would not necessarily pass it in a later year. This would occur simply due to the passage of time: in 2050, the forward rate used to discount benefits and costs from 2051 to 2050 would be higher than the one used in 2012 to discount benefits and costs from 2051 to 2050.

Of course, if new information became available that altered the DDR schedule, the analyst would need to reevaluate the ENPV of the program, just as he or she would do under the Ramsey approach. However, a reversal of the outcome of the benefit-cost analysis due to new information would not constitute time inconsistency. Newell and Pizer (2003) argue that when using historical data to estimate a DDR, an analyst should regularly update estimates of the DDR as more information becomes available, thus eliminating the problem of time inconsistency. Presumably, the same would occur under a Ramsey approach as actual consumption growth occurs and knowledge about the future growth rate changes. However, in practice, such updating of DDR schedules may occur only infrequently. ${ }^{43}$

\section{Concluding Remarks}

The use of a DDR in project evaluation would have important implications for how regulations are evaluated in the United States. Currently, the OMB requires that benefits and costs be discounted at a constant exponential rate, although a discount rate that is lower than the 3 percent and 7 percent that are currently required may be used to provide a sensitivity analysis when a project yields benefits to future generations. In contrast, France and the United Kingdom use DDR schedules in which all costs and benefits occurring in the same year are discounted at a rate that declines over time. Which approach is correct? This article has sought to clarify the arguments in favor of a DDR and to present recent empirical literature on the subject.

We have argued that theory provides compelling arguments for using a declining certaintyequivalent discount rate. In the Ramsey formula, uncertainty about the future rate of growth in per capita consumption can lead to a declining consumption rate of discount, assuming that shocks to consumption are positively correlated. This uncertainty in future consumption growth rates may be estimated econometrically based on historical observations, or it can be derived from subjective uncertainty about the mean rate of growth in mean consumption or its volatility.

The path from theory to a numerical schedule of discount rates requires estimates of $\delta$, $\eta$, and the process generating $g_{t}$. However, both France and the United Kingdom have

${ }^{43}$ For example, the UK discount rate schedule presented in Figure 3 has been in place since 2003 (HM Treasury 2003). 
been able empirically to implement a DDR that is at least partly based on the Ramsey model. ${ }^{44}$

The ENPV approach is less theoretically elegant and does not measure the consumption rate of discount as given by the Ramsey formula. It is, however, empirically tractable and, when expressed in consumption units, it corresponds to the approach currently recommended by the OMB for discounting net benefits (OMB 2003). The empirical ENPV literature has focused on models of the rate of return on long-term, high-quality government debt. Moreover, the literature concerning the United States suggests that the certainty-equivalent rate is declining with the time horizon. However, results from the empirical DDR literature are sensitive to the model estimated, the data series used to estimate the model, and how the data are smoothed and corrected for inflation.

Clearly, policymakers should use careful judgment in estimating a DDR schedule, whichever approach is used. Moreover, as emphasized earlier, the DDR schedule should be updated as time passes and more data become available. Establishing a procedure for estimating a DDR for project analysis would be an improvement over the OMB's current practice of recommending fixed discount rates that are rarely updated.

Appendix Table AI Maximum acceptable sacrifice from group A to increase income of group B by $\$$ I

\begin{tabular}{lcc}
\hline $\boldsymbol{\eta}$ & Group A Income $=\mathbf{2} *$ Group B Income & Group A Income $=\mathbf{I 0 *}$ Group B Income \\
\hline $\mathbf{0}$ & 1.00 & 1.00 \\
$\mathbf{0 . 5}$ & 1.41 & 3.16 \\
$\mathbf{I}$ & 2.00 & 10.00 \\
$\mathbf{I . 5}$ & 2.83 & 31.62 \\
$\mathbf{2}$ & 4.00 & 100.00 \\
$\mathbf{4}$ & 16.00 & 10000.00 \\
\hline
\end{tabular}

Source: Gollier, Koundouri, and Pantelidis (2008).

\section{References}

Arrow, K. J., W. R. Cline, K.-G. Maler, M.

Munasinghe, R. Squitieri, and J. E. Stiglitz. 1996.

Intertemporal equity, discounting, and economic efficiency. In Climate change 1995: Economic and social dimensions of climate change, contribution of Working Group III to the Second Assessment Report of the Intergovernmental Panel on Climate Change, ed. J. P. Bruce, H. Lee, and E. F. Haites.

Cambridge, UK: Cambridge University Press.

Atkinson, Giles, Simon Dietz, Jennifer Helgeson, Cameron Hepburn, and Håkon Sælen. 2009.

Siblings, not triplets: Social preferences for risk, inequality and time in discounting climate change.
Economics: The Open-Access, Open-Assessment EJournal 3 (2009-26).

Barro, Robert J. 2006. Rare disasters and asset markets in the twentieth century. Quarterly Journal of Economics 121: 823-66. 2009. Rare disasters, asset prices, and welfare costs. American Economic Review 99: 243-64.

Bates, J. M., and C. W. J. Granger. 1969. The combination of forecasts. Operational Research Quarterly 20: 451-68.

Cecchetti, Stephen G., Pok-sang Lam, and Nelson C. Mark. 2000. Asset pricing with

\footnotetext{
${ }^{44}$ The UK discounting schedule presented in Figure 3 assumes that $\delta=1.5$ and $\eta=1$ (HM Treasury, Annex 6 2003). The initial value of $g$ is 2 percent, implying $\rho=3.5$ percent. The DDR path is a step function that approximates the rate of decline in the discount rate in Newell and Pizer's random walk model (Oxera 2002). The French DDR is also tied to the Ramsey formula (Lebègue 2005).
} 
distorted beliefs: Are equity returns too good to be true? American Economic Review 90 (4): 787-805.

Cochrane, J. H. 1988. How big is the random walk in GNP? Journal of Political Economy 96: 893-920.

Dasgupta, Partha. 2008. Discounting climate change. Journal of Risk and Uncertainty 37: 141-69.

Dasgupta, P., S. A. Marglin, and A. Sen. 1972. Guidelines for project evaluation. New York: United Nations.

Epstein, L. G., and S. Zin. 1991. Substitution, risk aversion and the temporal behavior of consumption and asset returns: An empirical framework. Journal of Political Economy 99: 263-86.

Freeman, M. C., and B. Groom. Forthcoming. Positively gamma discounting: Combining the opinions of experts on the social discount rate. Economic Journal.

Freeman, M., B. Groom, K. Panipoulou, and T. Pantelides. 2013. Declining discount rates and the Fisher effect: Inflated past, discounted future. Centre for Climate Change Economics and Policy Working Paper No. 129.

Gollier, Christian. 2002. Time horizon and the discount rate. Journal of Economic Theory 107: 463-73.

2008. Discounting with fat-tailed economic growth. Journal of Risk and Uncertainty 37: 171-86.

. 2011. On the understanding of the precautionary effect in discounting. Geneva Risk and Insurance Review 36: 95-111.

\section{Pricing the planet's future:}

The economics of discounting in an uncertain world. Princeton, NJ: Princeton University Press.

Gollier, Christian, Phoebe Koundouri, and Theologos Pantelidis. 2008. Declining discount rates: Economic justifications and implications for long-run policy. Economic Policy 23: 757-95.

Gollier, C., and M. Weitzman. 2010. How should the distant future be discounted when discount rates are uncertain? Economics Letters 107 (3): 350-53.

Gollier, C., and R. Zeckhauser. 2005. Aggregation of heterogeneous time preferences. Journal of Political Economy 113 (4): 878-96.
Goulder, L. H., and R. Williams. 2012. The choice of discount rate for climate change policy evaluation. Climate Change Economics 3 (4): 1-18.

Groom, B., P. Koundouri, E. Panopoulou, and T. Pantelidis. 2007. Discounting the distant future: How much does model selection affect the certainty equivalent rate? Journal of Applied Econometrics 22: 641-56.

Groom, B., and D. Maddison. 2013. Non-identical quadruplets: Four new estimates of the elasticity of marginal utility for the UK. Grantham Research Institute on Climate Change Economics and the Environment, Working Paper No. 121. London School of Economics.

HM Treasury. 2003. Green book. http://www.hmtreasury.gov.uk/data_greenbook_index.htm (accessed June 6, 2014).

Heal, G. M. 2005. Intertemporal welfare economics and the environment. In Handbook of environmental economics, Vol. 3, ed. K.-G. Maler, and J. R. Vincent, 1105-45. Amsterdam: Elsevier North Holland.

Heal, Geoffrey, and Anthony Millner. 2013.

Discounting under disagreement. NBER Working Paper 18999.

Hepburn, C., P. Koundouri, E. Panopoulous, and T. Pantelidis. 2009. Social discounting under uncertainty: A cross-country comparison. Journal of Environmental Economics and Management 57: 140-150.

Jouini, E., J.-M. Marin, and C. Napp. 2010.

Discounting and divergence of opinion. Journal of Economic Theory 145: 830-59.

Kocherlakota, N. R. 1996. The equity premium: It's still a puzzle. Journal of Economic Literature 34: $42-71$.

Lebègue, Daniel. 2005. Révision du taux d'actualisation des investissements publics. Rapport du Groupe d'Experts, Commisariat Général du Plan. http://catalogue.polytechnique.fr/site.php?id=324\&. leid=2389 (accessed June 6, 2014).

Mankiw, G. 1981. The permanent income hypothesis and the real interest rate. Economics Letters 7: $307-11$.

Meyer, Donald, and Jack Meyer. 2005. Relative risk aversion: What do we know? Journal of Risk and Uncertainty 31: 243-62. 
Newell, R., and W. Pizer. 2003. Discounting the distant future: How much do uncertain rates increase valuations? Journal of Environmental Economics and Management 46 (1): 52-71.

Nordhaus, W. D. 1994. Managing the global commons: The economics of climate change. Cambridge, MA: MIT Press.

2007. The Stern review on the economics of climate change. Journal of Economic Literature 45 (3): 686-702.

Office of Management and Budget (OMB). 2003. Circular A-4: Regulatory analysis. Washington, DC: Executive Office of the President. http://www. whitehouse.gov/omb/circulars/ (accessed June 6, 2014).

Oxera. 2002. A social time preference rate for use in long-term discounting. Oxford, UK:

Office of the Deputy Prime Minister, Department for Transport and Department of the Environment, Food and Rural Affairs. http://www. communities.gov.uk/documents/corporate/pdf/ 146862.pdf (accessed June 6, 2014).

Pindyck, Robert S., and Neng Wang. 2013. The economic and policy consequences of catastrophes. American Economic Journal: Economic Policy 5 (4): 306-39.

Ramsey, F. P. 1928. A mathematical theory of saving. Economic Journal 38 (4): 543-49.

Stern, N. 2006. The economics of climate change:

The Stern review. Cambridge, UK: Cambridge University Press.

Sterner, T., M. Damon, and K. Mohlin. Forthcoming. Putting a price on the welfare of our children and grandchildren. In Cost-benefit analysis and environmental decision-making in developing and emerging countries, ed. M. A. Livermore, and R. L. Revesz. Oxford, UK, and New York: Oxford University Press.

Strotz, R. H. 1955. Myopia and inconsistency in dynamic utility maximization. Review of Economic Studies 23 (3): 165-80.

Thomas, L. B. 1999. Survey measures of expected U.S. inflation. Journal of Economic Perspectives 13: 125-44.

Tol, R. S. J. 2010. International inequity aversion and the social cost of carbon. Climate Change Economics 1 (1): 21-32.

Traeger, C. P. 2009. Recent developments in the intertemporal modeling of uncertainty. Annual Review of Resource Economics 1 (1): 26-85.

Weil, P. 1990. Nonexpected utility in macroeconomics. Quarterly Journal of Economics 105 (1): 29-42.

Weitzman, M. L. 1998. Why the far-distant future should be discounted at its lowest possible rate. Journal of Environmental Economics and Management 36: 201-8. 2001. Gamma discounting. American Economic Review 91: 260-71.

- 2004. Discounting a distant future whose technology is unknown. http://www.sv. uio.no/econ/forskning/aktuelt/arrangementer/ torsdagseminaret/2004/torsdag-v04/weitzman-1.pdf (accessed June 6, 2014).

2007. Subjective expectations and assetreturn puzzles. American Economic Review 97: 1102-30. 